\title{
P-1186 - THE RECOVERY PROCESS OF PERSONS LIVING WITH PSYCHIATRIC DISABILITIES: VALUES AND PRINCIPLES OF NOVA AURORA COMMUNITY ASSOCIATION PSYCHOSOCIAL REHABILITATION PROGRAM
}

\author{
A.J.Marques, A.Morais, F.Campos, M.Silva, L.Silva, R.Almeida \\ ${ }^{1}$ Laboratório de Reabilitação Psicossocial, Faculdade de Psicologia e de Ciências da Educação da \\ Universidade do Porto e Escola Superior de Tecnologia da Saúde do Instituto Politécnico do Porto, ${ }^{2}$ \\ Associação Nova Aurora na Reabilitação e Reintegração Psicossocial, Porto, Portugal
}

Introduction: The Nova Aurora Community Association psychosocial rehabilitation program was developed based in the most current values of Psychosocial Rehabilitation. Some nuclear assumptions were considered, such as a) suppressing the disease stigma, b) defocusing from the mental ill role, promoting empowerment and self-determination, c) developing personal competencies directly related to the individuals' social integration specific context (readiness, cognitive, social, emotional stress management, employability).

Purpose: To present the rational of this program and the outcomes of a pilot study designed to test if this psychiatric rehabilitation program effectively helps persons living with psychiatric disabilities become more successful and satisfied in living, learning, working, and social environments of their choice.

Methods: The program is being implemented for 13 months to 38 persons living with psychiatric disabilities and it is developed in 2 main levels: a) tranversal competencies (neurocognitive, stress and illness management, healthy lifestyle, self efficacy and anti-self-stigma); b) specific competencies directly related to the individuals' social integration specific context (employability/ housing, social cognition, etc). All users still frequent an empowerment center and develop sport and leisure activities. It is also available home support and family psicoeducation. The program effectiveness assessment integrated pre and post tests, evaluating all these different functional domains and life quality and program satisfaction.

Results: Preliminary results point towards very positive outcomes, specifically regarding personal competencies development, satisfaction level with the program, reduction of relapse, and absence rates.

Conclusions: Although these results are promising, this research is an initial step in establishing the efficiency of this rehabilitation program. 